\title{
Biophysical Parameters and Actual Evapotranspiration of Bean Culture by Means of Remote Sensing
}

\author{
Allisson Lucas Brandão Lima ${ }^{1}$, Roberto Filgueiras ${ }^{1}$, Everardo Chartuni Mantovani ${ }^{1}$, Daniel Althoff ${ }^{1}$, \\ Robson Argolo dos Santos ${ }^{1} \&$ Luan Peroni Venancio ${ }^{1}$ \\ ${ }^{1}$ Department of Agricultural Engineering, Federal University of Viçosa, Viçosa, Brazil \\ Correspondence: Allisson Lucas Brandão Lima, Depatament of Agricultural Engineering, Federal University of \\ Viçosa, Viçosa, 36570-900, Brazil. Tel: 55-313-899-2732. E-mail: allisson.lima@ufv.br
}

Received: April 23, 2019

doi:10.5539/jas.v11n13p156
Accepted: June 1, 2019 Online Published: August 15, 2019

URL: https://doi.org/10.5539/jas.v11n13p156

The research is financed by Coordenação de Aperfeiçoamento de Pessoal de Nivel Superior (CAPES, Brazil-Finance code 001) and Conselho Nacional de Desenvolvimento Científico e Tecnológico (CNPq, Brazil).

\begin{abstract}
Agricultural irrigation is involved in an important chain that involves all sectors of the economy, either directly, by increasing food production, or indirectly, by withdrawing large amounts of fresh water. The relevance of this theme forces the search for alternatives to make water use as rational as possible. Evapotranspiration estimation methods based in remote sensing, such as the SAFER (Simple Algorithm for Evapotranspiration Retrieving) model, become extremely relevant in these scenarios, since it is possible to estimate this parameter in large scales. Therefore, the aim of this research was to apply the SAFER model in the estimation of bean crop actual evapotranspiration using Landsat-8 satellite image data. One of the parameters used as input in the SAFER model is the NDVI (Normalized Difference Vegetation Index), which presented a coefficient of determination $\left(\mathrm{r}^{2}\right)$ equal to 0.80 when compared to the crop coefficient. The actual evapotranspiration (ETa) estimated by the SAFER model were compared to the FAO 56 model estimates for later correlation between the models. This information is expected to assist the producer in a better management of water resources used in irrigation. The correlation between the two models presented a relevant coefficient of determination $\left(r^{2}=0.73\right)$, representing the potential of the SAFER model in relation to the FAO model 56.
\end{abstract}

Keywords: evapotranspiration, SAFER, FAO 56, crop coefficient, Landsat-8

\section{Introduction}

Approximately $70 \%$ of all freshwater in the world is destinated to agriculture, which makes it relevant to adopt more efficient and sustainable practices in the monitoring and management of water resources, especially in irrigated areas. In order to turn the irrigation feasible, we must seek sustainable practices, reducing conflicts among its users. A rational use will also reduce the electric energy cost to pump water in irrigated fields, which is the main responsible for food production expenditures (Greenland, Dalrymple, Levin, \& O’Mahony, 2018).

The world food production needs to be raised by $85 \%$ to feed the estimated 9.6 billion people by 2050 (DeSA, 2013). In this scenario, irrigation is one of the main technologies with the potential to increase food production. Under Brazilian conditions, irrigated agriculture has an average productivity of at least 2.7 times larger than of rainfed agriculture (Borghetti, Silva, Nocko, Loyola, \& Chianca, 2017). However, it is necessary to practice it with caution.

The water application criteria for crops is determined by irrigation management, whose parameters are related to soil, plant and atmosphere. Among the main irrigation management methods, it is worth mentioning the management via soil, via plant and via climate. The management via soil and via plant are more difficult to apply and, consequently, more expensive. On the other hand, the irrigation management via climate is highlighted by its greater economic feasibility and practicality in its execution, being widely applied.

In management via climate, the irrigation depths can be determined from the product between the reference evapotranspiration (ETo), crop coefficient (Kc) and water stress coefficient (Ks), which combine in the actual 
crop evapotranspiration (ETa) (Bernardo, Soares, \& Mantovani, 2006). However, management via climate has the disadvantage of considering the climate of the whole agricultural system as homogeneous.

Currently, the development of new technologies makes it possible to spatially detail the estimates of crops water demands, a fact that makes remote sensing relevant in this matter. Thus, the monitoring of crops, as well as the management of the water demand through climate with remote sensing subsidy, has become popular, since it allows estimating the actual evapotranspiration of the crop spatially. For this, data from remote sensors, such as the ones onboard of satellites and unmanned aerial-vehicles, are used to estimate the ETa, ensuring efficient decision-making during irrigation management (Herman et al., 2018; Ma et al., 2018).

In order to determine ETa, some algorithms have already been developed and are frequently applied. Among them, the most common are the SEBAL, elaborated by Bastiaanssen, Menenti, Feddes, and Holtslag (1998), and METRIC, elaborated by Allen, Tasumi, and Trezza (2007). The SAFER model, which was elaborated by A. H. de C. Teixeira (2010), has also been applied due to its operability.

SAFER has a simple parameterization, which makes this algorithm to have operational efficiency in the estimation of ETa in commercial properties. This fact provides the SAFER enormous potential to meet the recurring demands of large irrigated producers, who are always looking for new technologies and for greater profitability of their crops.

Based on the need to monitor irrigated crops more accurately and on the high parsimony found in the SAFER algorithm, the objective of this work was to estimate the ETa and the bean crop coefficient throughout the crop season.

\section{Material and Methods}

\subsection{Study Area}

The study area is located in the western of the state of Bahia, more precisely in the municipality of São Desidério (Figure 1). The region has tropical climate with dry season, Aw, according to the Köppen classification (Alvares et al., 2013). The study area comprises seven central pivots inscribed in a surrounding rectangle with the following pairs of plane coordinates: $8.583 .625 \mathrm{~S} ; 465.165 \mathrm{~W}$ and $8.592 .325 \mathrm{~S} ; 481.575 \mathrm{~W}$ (coordinate reference system: SIRGAS 2000 Projection UTM 23S). The total area of the seven central pivots is approximately 900 ha.

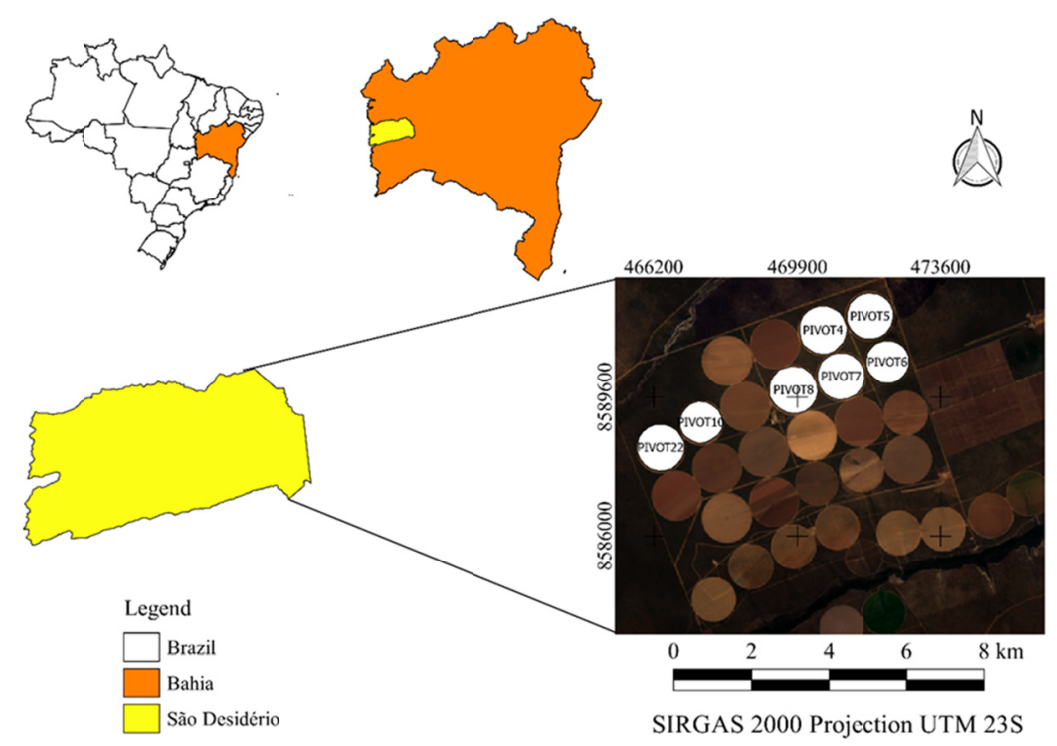

Figure 1. Location of the study area in relation to the municipality of São Desidério, Bahia state and Brazil

\subsection{Field Data}

The daily air humidity $(\%)$, maximum $\left({ }^{\circ} \mathrm{C}\right)$ and minimum $\left({ }^{\circ} \mathrm{C}\right)$ air temperature, wind speed $\left(\mathrm{m} \mathrm{s}^{-1}\right)$ and incident solar radiation $\left(\mathrm{MJ} \mathrm{m}^{-2} \mathrm{~d}^{-1}\right)$ were collected by a meteorological station installed in the study area. These parameters allowed the calculation of reference evapotranspiration (ETo) from the Penman Monteith equation (PM), which is considered as standard by FAO-56 (Allen, Pereira, Raes, \& Smith, 1998). 
In the field, data were collected regarding: number of active central pivots in the crop season, area of each pivot, bean cultivars, sowing date and irrigation cut-off date (when irrigation management was suspended).

\subsection{Orbital Data}

In order to calculate evapotranspiration using the SAFER model, we selected the images available for the crop season. The satellite used was the Landsat- 8 , which have the Operational Land Imager (OLI) sensor and Thermal Infrared Sensor (TIR). The Landsat- 8 with these two sensors have the following spatial resolution: panchromatic with $15.0 \mathrm{~m}$ (band 8); multispectral with $30.0 \mathrm{~m}$ (bands 1-7 and 9); and thermal with $100.0 \mathrm{~m}$ (bands 10-11), all with a temporal resolution of 16 days. It is noteworthy that the thermal images were already re-scaled for 30 meters due to the level of processing of the product used. These images were acquired through the online platform Earth Explorer, which is maintained by the USGS (United States Geological Survey) and NASA (National Aeronautics and Space Administration).

\subsection{Orbital Data Selection}

Each of the satellite images obtained during the crop cycle had their cloudiness verified for the study area. All the images that presented clouds in the area of study were eliminated, because the clouds could compromise the image data analysis and consequently the ETa modeling by the algorithm. A total of five cloud-free images were obtained among the dates related to the interval of sowing until the irrigation suspension, for the year 2015, according to Table 1 .

Table 1. Central pivots area and respective dates of sowing and irrigation suspension

\begin{tabular}{llll}
\hline Pivot & Area (ha) & Sowing Date & Irrigation Suspension \\
\hline 4 & 140 & $05 / 06 / 2015$ & $22 / 08 / 2015$ \\
5 & 130 & $18 / 06 / 2015$ & $05 / 09 / 2015$ \\
6 & 120 & $26 / 06 / 2015$ & $07 / 09 / 2015$ \\
7 & 130 & $11 / 06 / 2015$ & $29 / 08 / 2015$ \\
8 & 130 & $28 / 05 / 2015$ & $16 / 08 / 2015$ \\
10 & 120 & $20 / 05 / 2015$ & $12 / 08 / 2015$ \\
22 & 130 & $22 / 05 / 2015$ & $10 / 08 / 2015$ \\
\hline
\end{tabular}

\subsection{Pre-processing of Orbital Data}

The images were initially pre-processed to radiometric conversion, which transforms the digital numbers of radiance to apparent reflectance. Afterwards, the images were submitted to an atmospheric correction with the application of the DOS methodology (Dark Object Subtraction), which was developed by Chavez Jr (1988). These steps were done in the QGIS software (2.14.19-ESSEN) and for these we used the Semi-Automatic Classification Plugin developed by Congedo (2016).

\subsection{SAFER Algorithm}

The images for the subsequent estimation of the evapotranspirative ratio (R), algebraic operations were performed with the required bands to obtain the Normalized Difference Vegetation Index (NDVI), surface albedo $\left(\alpha_{0}\right)$ and surface temperature (Ts). All the steps are shown in the flow chart (Figure 2). 


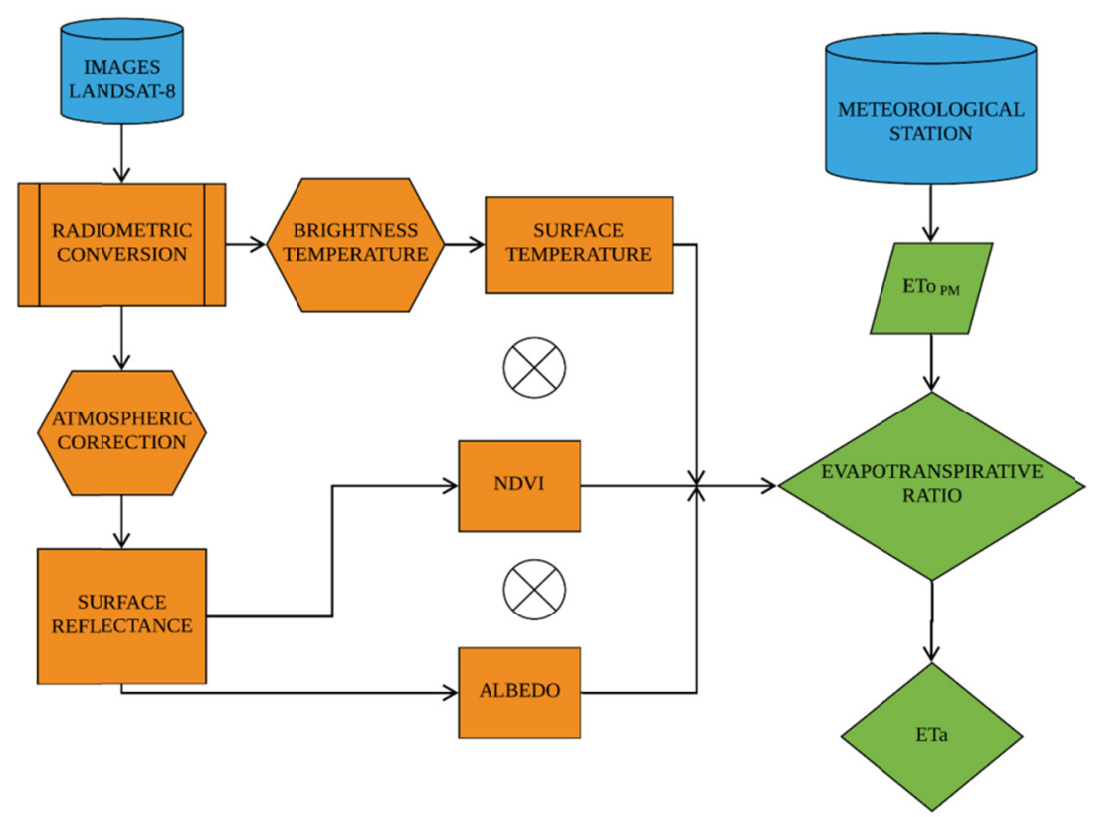

Figure 2. Procedure performed during the execution of the work

To calculate the NDVI, the bands 4 and 5 were processed according to Equation 1, developed by Rouse Jr, Haas, Schell, and Deering (1974).

$$
\mathrm{NDVI}=\frac{\rho_{5}-\rho_{4}}{\rho_{5}+\rho_{4}}
$$

where, $\rho 4$ : surface reflectance for band 4, red part of spectrum electromagnetic $(640-690 \mathrm{~nm})$; $\rho 5$ : surface reflectance related to band 5, near infrared part of spectrum electromagnetic $(850-880 \mathrm{~nm})$.

Subsequently, to estimate the planetary albedo, the bands 2 to 7 and corresponding band weights were used (Equation 2). Band weights have already been calculated, calibrated and made available by Silva et al. (2016). The albedo was then corrected for surface albedo, according to Equation 3. This variable has great importance in global and regional climate monitoring, since it permits to study the dynamics of bodies in the heat exchange, having as general definition the energy portion reflected and/or emitted by a body, varying from 0 to 1 , where 1 represents the total energy reflection (Zhang, Liu, He, Lian, \& Cui, 2017).

$$
\alpha_{\text {top }}=\sum_{\mathrm{i}=2}^{7} \mathrm{w} \rho
$$

where, $\alpha_{\text {top }}$ : planetary albedo; $\rho$ : reflectance of the bands (1-7); weight for each band.

$$
\alpha_{0}=\alpha_{\text {top }} 0.61+0.08
$$

where, $\alpha_{0}$ : surface albedo

Then, the surface temperature was calculated according to Equation 4.

$$
\mathrm{T}_{0}=1.11 \mathrm{~T}_{\mathrm{b}}-31.89
$$

where, $T_{0}$ : surface temperature; $T_{b}$ : Brightness Temperature.

With the parameters estimated, it is possible to perform correlations with the vegetal cover of the surface. The NDVI, surface albedo and surface temperature combined were applied to obtain the evapotranspirative ratio (R), according to Equation 5. This algorithm used the Penman-Monteith equation to estimate the ETa, and was developed by A. H. de C. Teixeira (2010) for large-scale application.

$$
\mathrm{R}=\exp \left[\mathrm{a}+\mathrm{b}\left(\frac{\mathrm{To}}{\alpha \mathrm{NDVI}}\right)\right]
$$

where, $\mathrm{a}$ and $\mathrm{b}$ are empirical coefficients and correspond to 1.8 and -0.008 , respectively.

The coefficients were empirically calibrated to the Brazilian semiarid region (A. de C. Teixeira, Hernandez, Lopes, Scherer-Warren, \& Bassoi, 2014).

Finally, for the estimation of the actual evapotranspiration of the crop (Equation 6), the Penman-Monteith reference evapotranspiration was used. 


$$
\mathrm{ETa}=\mathrm{ETo} \mathrm{R}
$$

where, ETo: Reference evapotranspiration, estimated according to the Penman-Monteith-FAO 56 (Allen et al., 1998), according to the Equation 7.

$$
\mathrm{ETo}=\frac{0.408 \Delta(\mathrm{Rn}-\mathrm{G})+\frac{\gamma 900 \mathrm{U} 2\left(\mathrm{e}_{\mathrm{s}}-\mathrm{e}_{\mathrm{a}}\right)}{\mathrm{T}+273}}{\Delta+\gamma\left(1+0.34 \mathrm{u}_{2}\right)}
$$

Where, $\Delta$ is the slope of the vapor pressure curve; Rn: daily net radiation; G: daily total soil heat flux; $\gamma$ : psychrometric constant; $\mathrm{u}_{2}$ : wind speed at 2 meters high; $\mathrm{e}_{\mathrm{s}}$ saturation vapor pressure; $\mathrm{e}_{\mathrm{a}}$ : actual vapor pressure; $\mathrm{T}$ : average air temperature at 2 meters high.

\subsection{Model Validation}

The model SAFER was validated with the estimates of ETc according to FAO 56 (Equation 8), since no directed measures of real evapotranspiration were available. The calculated ETo was multiplied by the crop coefficient that best represented the crop in the field (time of the passage of the image), according to the assumptions established in Allen et al. (1998).

$$
\mathrm{ETc}=\mathrm{Kc} \cdot \mathrm{ETo}
$$

Where, ETc: crop evapotranspiration; Kc: crop coefficient.

The bean crop coefficient corresponding to the days of the images was estimated using the methodology described by FAO 56.

\subsection{Linear Regression With NDVI Data to Estimate Kc}

The Kc was estimated according to the methodology presented in Allen et al. (1998). A linear regression was performed with the Kc value as the dependent variable and the NDVI as the independent variable. This regression was performed to fit a practical model to estimate Kc of bean crop from satellite images.

\subsection{Statistical Analysis}

The data of FAO ETc were considered as observed values and the data obtained by the SAFER algorithm as predicted values. Thus, the predicted values were compared to those observed using the statistical metrics: coefficient of determination ( $\mathrm{r}^{2}$ ) (Richter, Hank, Atzberger, \& Mauser, 2011), Root Mean Square Error (RMSE) (Neville \& Kennedy, 1964), Nash-Sutcliffe Efficiency (NSE) (Nash \& Sutcliffe, 1970), Mean bias error (MBE) (Richter, Hank, Atzberger, \& Mauser, 2011) and absolute mean error (MAE) (Willmott \& Matsuura, 2005) according to Equations 9, 10, 11, 12 and 13, respectively.

$$
\begin{gathered}
r^{2}=\frac{\left[\sum_{i=1}^{n}\left(\mathrm{P}_{i}-\overline{\mathrm{P}}\right)\left(\mathrm{O}_{\mathrm{i}}-\overline{\mathrm{O}}\right)\right]^{2}}{\left[\sum_{\mathrm{i}=1}^{\mathrm{n}}\left(\mathrm{P}_{\mathrm{i}}-\overline{\mathrm{P}}\right)^{2}\right]\left[\sum_{\mathrm{i}=1}^{\mathrm{n}}\left(\mathrm{O}_{\mathrm{i}}-\overline{\mathrm{O}}\right)^{2}\right]} \\
\mathrm{RMSE}=\sqrt{\frac{\sum_{\mathrm{i}=1}^{\mathrm{n}}\left(\mathrm{O}_{\mathrm{i}}-\mathrm{P}_{\mathrm{i}}\right)^{2}}{\mathrm{n}}} \\
\text { RMSE }=\sqrt{\frac{\sum_{\mathrm{i}=1}^{\mathrm{n}}\left(\mathrm{O}_{\mathrm{i}}-\mathrm{P}_{\mathrm{i}}\right)^{2}}{\mathrm{n}}} \\
\text { MBE }=\frac{1}{\mathrm{n}} \sum_{\mathrm{i}=1}^{\mathrm{n}}\left(\mathrm{P}_{\mathrm{i}}-\mathrm{O}_{\mathrm{i}}\right) \\
\text { MAE }=\frac{1}{\mathrm{n}} \sum_{\mathrm{i}=1}^{\mathrm{n}}\left|\mathrm{P}_{\mathrm{i}}-\mathrm{O}_{\mathrm{i}}\right|
\end{gathered}
$$

where, $\mathrm{P}_{\mathrm{i}}$ is the value predicted by the model; $\mathrm{O}_{\mathrm{i}}$ : observed value; $\overline{\mathrm{O}}$ : mean values observed and $\mathrm{n}$ : numbers of data pairs.

\section{Results and Discussion}

The NDVI values of the analyzed central pivots are show in Figure 3. NDVI has been used in several studies in the analysis of the condition of natural or agricultural vegetation. The main factor for its adoption is the portion of energy reflected by the leaf in the region of red and the near infrared. The quantifications of these reflected energies will generate the NDVI, ranging from -1.0 (e.g., water clean) to +1.0 (e.g., green vegetation and dense cover). Analyzing Figure 3, it is possible to verify the development of the bean crop as well as the condition of the vegetation throughout the crop cycle. In practical terms, it's possible to affirm that the NDVI has the ability to indirectly demonstrate the photosynthetic efficiency of a plant and its progress, since it has a strong correlation with its physiological development (Bellón, Bégué, Lo Seen, de Almeida, \& Simões, 2017; Robinson et al., 2017). 


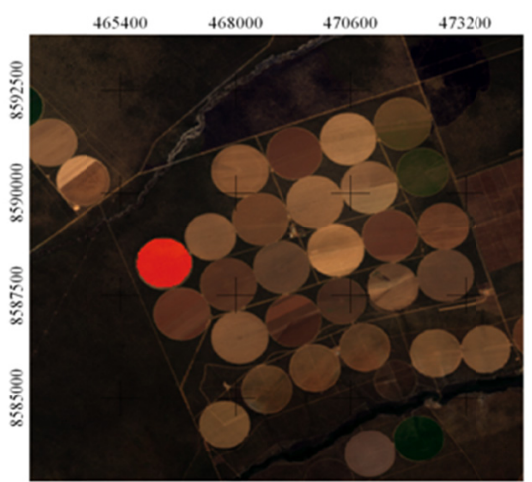

$25 / 05 / 2015$

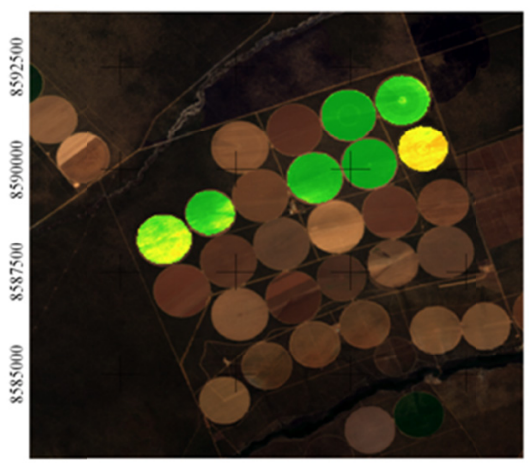

$28 / 07 / 2015$

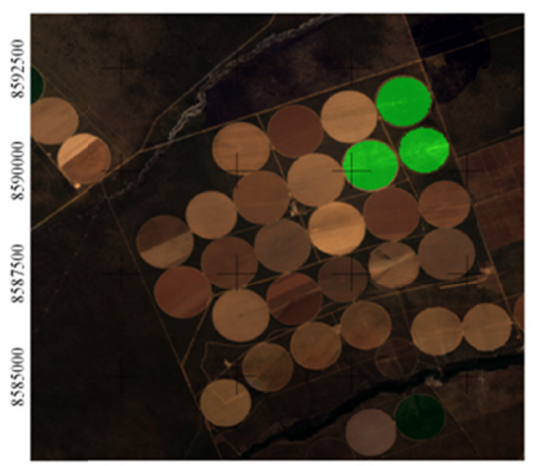

$29 / 08 / 2015$

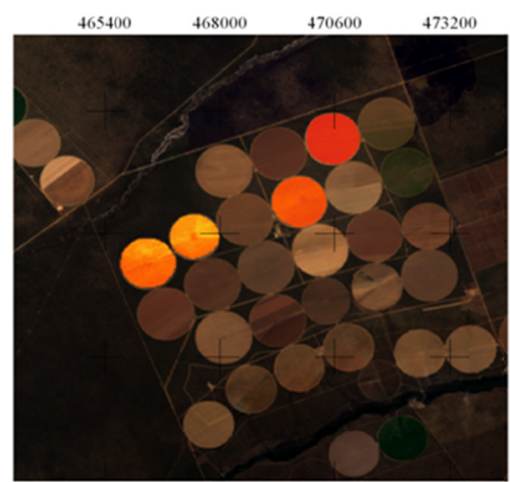

$10 / 06 / 2015$

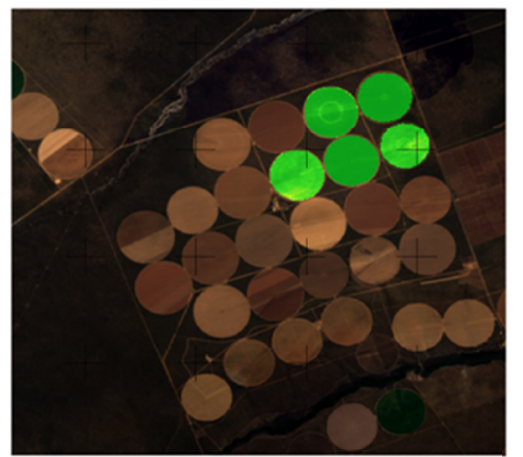

$13 / 08 / 2015$

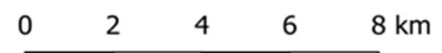

Legend

NDVI

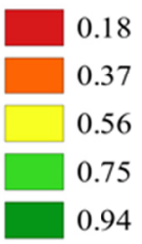

SIRGAS 2000 Projection

UTM $23 \mathrm{~S}$

0.94

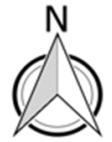

Figure 3. NDVI of the bean culture in different physiological stages

For the image of $10 / 06 / 2015$, the average values of NDVI were $0.23 ; 0.30 ; 0.43$ and 0.38 for the central pivots $04,08,10,22$, respectively. For the image of 28/07/2015 the average values of this index were $0.89 ; 0.80 ; 0.53$; $0.91 ; 0.78 ; 0.83$ and 0.62 for the pivots $4,5,6,7,8,10,22$ respectively. These values well-represent the initial and reproductive phase of the bean for each of the analyzed central pivots.

The image of the day 29/08/2015 presented clouds above central pivots number 02 and 10 . Thus, the analysis was not performed for these central pivots in this day. Clouds are a big problem when working with orbital images, making it important combine two or more compatible sensors (e.g., Landsat 7 and 8) or also utilize unmanned aerial vehicle (UAV) to get around this problem.

Cloudiness is a major obstacle to the agricultural monitoring by means of satellites that capture electromagnetic radiation at the optical range, since they are subject to cloud interference. This fact has motivated several researchers to commit themselves to the development of methodologies to overcome this issue (Abascal Zorrilla, Vantrepotte, Gensac, Huybrechts, \& Gardel, 2018; Dusseux, Corpetti, Hubert-Moy, \& Corgne, 2014). Another alternative is the use of unmanned aerial vehicles (UAV), since it flies and capture images of surface at altitudes below the clouds. This complementary measure is important, because it has low cost and images availability are independent to clouds presence (Wahab, Hall, \& Jirström, 2018). 
Another option would be to complement the Landsat 8 images with Sentinel 2A and 2B satellite images, providing more coherent and reliable results for possible decision-making in irrigation management. The Sentinel 2 constellation has onboard the Multispectral Instrument (MSI) sensor that presents temporal resolution of 10 days and spatial resolution of 10, 20 and 60 meters, depending on the band (Drusch et al., 2012). However, it does not have a specific sensor to capture the radiation in the thermal region, necessary for the estimation of the evapotranspiration using SAFER. In a recent study, Filgueiras et al. (2019) developed a methodology to overcome this problem. These authors estimated the surface temperature (Ts) for Sentinel 2A and 2B, which allows the estimation of actual evapotranspiration with these satellites. After analyzing the NDVI images (Figure 3) it was possible to establish, by means of a simple linear regression (Figure 4), a relationship between the Kc-FAO of the bean and the mean NDVI of the pivots. This relationship between the variables showed to be close $\left(r^{2}=0.8014\right)$, which explains the growth and phenological progress of the culture. Similar results were found by Toureiro, Serralheiro, Shahidian and Sousa (2017) for the corn crop. These authors found a coefficient of determination equal to 0.82 between the two variables. Alface, Pereira, Filgueiras, and Cunha, (2019) obtained a coefficient of determination equal to 0.71 for sugarcane cultivation in the Republic of Mozambique, a country located in southeastern Africa.

It is possible to see that some NDVI values are not consistent with the crop coefficient (Figure 4). Unlike NDVI, the standard Kc modeling does not consider field factors that affect the crop temporally and spatially, such as the phytosanitary issues of crops and soil moisture, represented by the water stress coefficient (KSW).

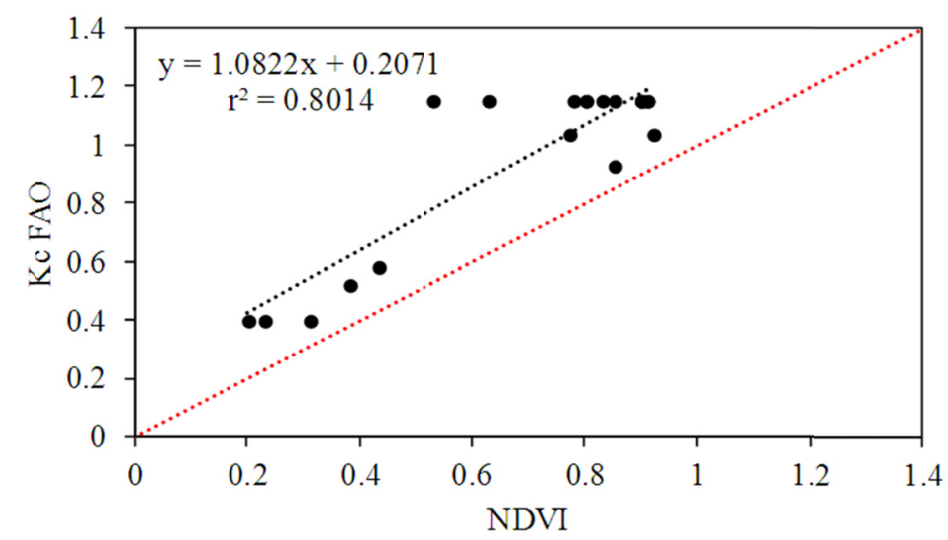

Figure 4. Performance of the NDVI in relation to the Kc of the bean culture according to the sequence of the images obtained and the variation of $\mathrm{Kc}$ as a function of the cycle

Figure 5 shows the ETa data for five different dates over season. The maximum value between the pivots was $7.82 \mathrm{~mm} \mathrm{day}^{-1}$, referring to the apex of evapotranspiration of the crop in the cycle, which can be seen for the central pivots 5 and 7 in the image of 13/08/2015. 


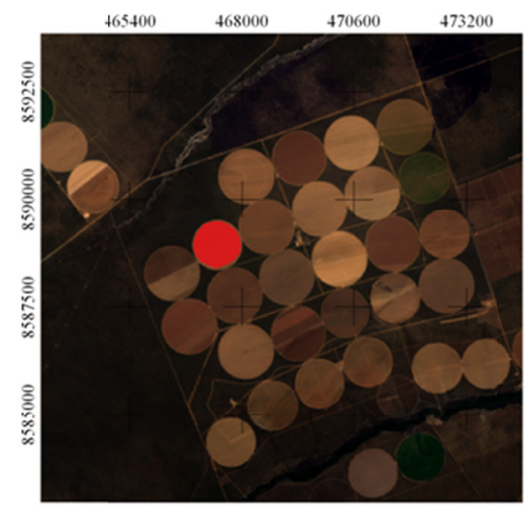

$25 / 05 / 2015$

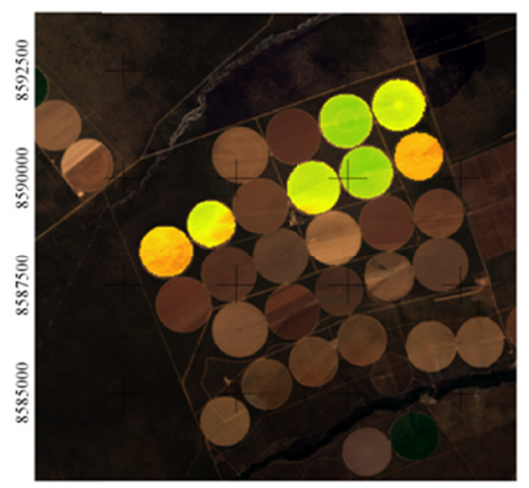

$28 / 07 / 2015$

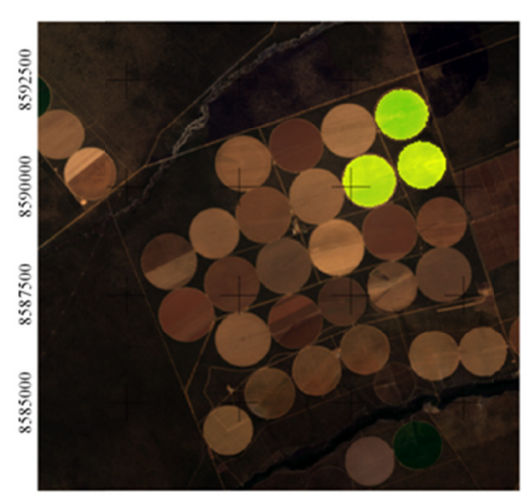

$29 / 08 / 2015$

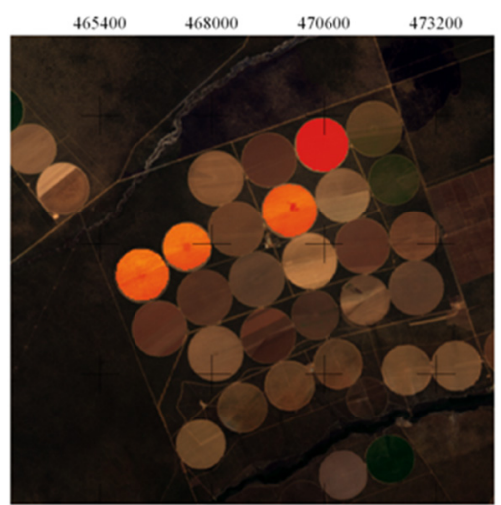

$10 / 06 / 2015$

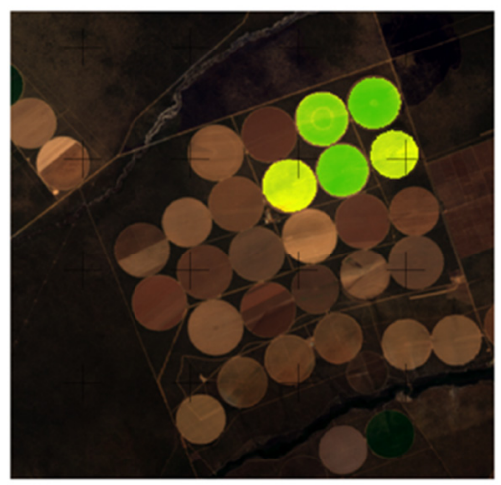

$13 / 08 / 2015$

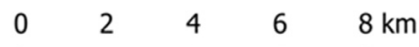

Legend

ETa SAFER (mm day-1)

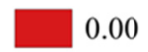

1.95

3.91

5.86

7.82

SIRGAS 2000 Projection

UTM $23 \mathrm{~S}$

Figure 5. ETa values for five different dates over season estimated according to the SAFER algorithm

Similar to the NDVI, the ETa (FAO and SAFER) gradually increases according to the development of the culture (Figure 5). Thus, the models were compared using a simple linear regression equation shown in Figure 6. 


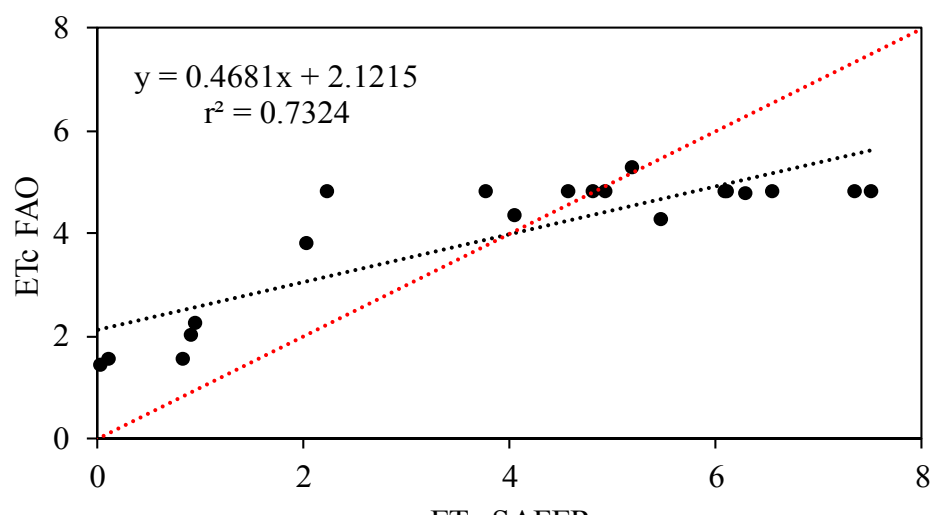

ETa SAFER

Figure 6. Linear regression between ETa SAFER medium and ETc FAO

The dependence between the two models of evapotranspiration estimation proved more satisfactory in the mid-season because, as described, there is an underestimation of the actual evapotranspiration in the initial phase of the growth cycle. This fact occurs due to the low number of images obtained without the presence of clouds, besides the errors related to the calculation of the ETa SAFER during in the initial phase development, since the algorithm ponders the NDVI in parameterization. This fact is related to the area with absence or scarce vegetation, presenting greater exposed soil area.

Table 2 shows the values of the metrics used to compare ETc estimated by SAFER with the ETc FAO (considered as standard). MBE presented a value very close to zero $\left(-0.01 \mathrm{~mm} \mathrm{day}^{-1}\right)$, indicating that, overall, no under or overestimation occurs in the data. However, if analyzed the Figure 6, it's possible to clearly see that, when ETc FAO is greater than $5 \mathrm{~mm} \mathrm{day}^{-1}$, the SAFER model overestimates and, and when FAO is close to 2 $\mathrm{mm} \mathrm{day}^{-1}$, it underestimates. Because this, MBE should be interpreted cautiously because positive and negative errors will cancel out. According to Sales et al. (2018), the problem of SAFER underestimates is due to presence of soils with little vegetation, resulting in low values of NDVI and high values of temperature, leading to low values of R (Equation 5) and, consequently, low ETa values.

Table 2. Table with comparison of the metrics values between SAFER and FAO models

\begin{tabular}{ll}
\hline Statistical Metrics & Values \\
\hline MAE $\left(\mathrm{mm} \mathrm{day}^{-1}\right)$ & 1.22 \\
$\operatorname{MBE}\left(\mathrm{mm} \mathrm{day}{ }^{-1}\right)$ & -0.01 \\
$\operatorname{RMSE}\left(\mathrm{mm} \mathrm{day}^{-1}\right)$ & 1.45 \\
NSE & 0.65 \\
\hline
\end{tabular}

In the work of Moriasi et al. (2007), the NSE was classified as good between 0.65 and 0.75 , a fact that makes the SAFER algorithm satisfactory when compared to the standard method, despite all the field obstacles to estimate ETa. The RMSE with a value of $1.45 \mathrm{~mm}^{-1 a y}$ and the MAE with a value of $1.22 \mathrm{~mm}^{-1}$ day $^{-1}$ demonstrate the $^{-1}$ existence of considerable dispersion from observed values. This fact indicates the need for caution when assessing values estimated by SAFER, since the RMSE and MAE values do not effectively represent the behavior during part of the cycle. Only a few images were obtained and, as previously mentioned, the initial phase presented a high estimation error. The statistical metrics highlights the importance of the SAFER algorithm calibration for agricultural areas and crops. Despite the model being empirically calibrated to the semiarid and presenting good predictive power, it is not accurate, as showed by the RMSE and MAE values.

\section{Conclusion}

1) The SAFER methodology along with the NDVI images allowed the extraction of important information about the crop. This information helps in the verification of problems occurring in the fields, as well as in the control of irrigation through the bean actual evapotranspiration.

2) NDVI presented a very close relationship with bean growth cycle, which allows the monitoring of current crop information. Besides that, it resembles satisfactorily the Kc of the bean crop in the study area. 
3) In general terms, SAFER model suffers a lot of soil influence in the initial phase, impairing the analysis and results in this period, but presenting good predictive capacity of ETa for bean crop.

\section{References}

Abascal Zorrilla, N., Vantrepotte, V., Gensac, E., Huybrechts, N., \& Gardel, A. (2018). The Advantages of Landsat 8-OLI-Derived Suspended Particulate Matter Maps for Monitoring the Subtidal Extension of Amazonian Coastal Mud Banks (French Guiana). Remote Sensing, 10(11), 1733. https://doi.org/ $10.3390 / \mathrm{rs} 10111733$

Alface, A. B., Pereira, S. B., Filgueiras, R., \& Cunha, F. F. (2019). Sugarcane spatial-temporal monitoring and crop coefficient estimation through NDVI. Revista Brasileira de Engenharia Agrícola e Ambiental, 23(5), 330-335. https://doi.org/10.1590/1807-1929/agriambi.v23n5p330-335

Allen, R. G., Pereira, L. S., Raes, D., \& Smith, M. (1998). FAO Irrigation and drainage paper No. 56. Rome: Food and Agriculture Organization of the United Nations.

Allen, R. G., Tasumi, M., \& Trezza, R. (2007). Satellite-based energy balance for mapping evapotranspiration with internalized calibration (METRIC)-Model. Journal of Irrigation and Drainage Engineering, 133(4), 380-394. https://doi.org/10.1061/(ASCE)0733-9437(2007)133:4(395)

Alvares, C. A., Stape, J. L., Sentelhas, P. C., de Moraes, G., Leonardo, J., \& Sparovek, G. (2013). Köppen’s climate classification map for Brazil. Meteorologische Zeitschrift, 22(6), 711-728. https://doi.org/10.1127/ 0941-2948/2013/0507

Bastiaanssen, W. G., Menenti, M., Feddes, R., \& Holtslag, A. (1998). A remote sensing surface energy balance algorithm for land (SEBAL). 1. Formulation. Journal of Hydrology, 212, 198-212. https://doi.org/10.1016/ S0022-1694(98)00253-4

Bellón, B., Bégué, A., Lo Seen, D., de Almeida, C., \& Simões, M. (2017). A Remote Sensing Approach for Regional-Scale Mapping of Agricultural Land-Use Systems Based on NDVI Time Series. Remote Sensing, 9(6), 600. https://doi.org/10.3390/rs9060600

Bernardo, S., Soares, A. A., \& Mantovani, E. C. (2006). Manual de irrigação. Viçosa: UFV.

Borghetti, J., Silva, W., Nocko, H., Loyola, L., \& Chianca, G. (2017). Agricultura irrigada sustentável no Brasil: Identificação de áreas prioritárias. FAO, Brasília.

Chavez Jr, P. S. (1988). An improved dark-object subtraction technique for atmospheric scattering correction of multispectral data. Remote Sensing of Environment, 24(3), 459-479. https://doi.org/10.1016/0034-4257(88) 90019-3

Congedo, L. (2016). Semi-automatic classification plugin documentation. Release, 4(0.1), 29.

DeSA, U. (2013). World population prospects: The 2012 revision (p. 18). Population Division of the Department of Economic and Social Affairs of the United Nations Secretariat, New York.

Drusch, M., Del Bello, U., Carlier, S., Colin, O., Fernandez, V., Gascon, F., ... Martimort, P. (2012). Sentinel-2: ESA's optical high-resolution mission for GMES operational services. Remote Sensing of Environment, 120, 25-36. https://doi.org/10.1016/j.rse.2011.11.026

Dusseux, P., Corpetti, T., Hubert-Moy, L., \& Corgne, S. (2014). Combined Use of Multi-Temporal Optical and Radar Satellite Images for Grassland Monitoring. Remote Sensing, 6(7), 6163-6182. https://doi.org/ $10.3390 /$ rs6076163

Filgueiras, R., Mantovani, E. C., Dias, S. H. B., Fernandes Filho, E. I., Cunha, F. F. da, \& Neale, C. M. U. (2019). New approach to determining the surface temperature without thermal band of satellites. European Journal of Agronomy, 106, 12-22. https://doi.org/10.1016/j.eja.2019.03.001

Greenland, S. J., Dalrymple, J., Levin, E., \& O’Mahony, B. (2018). Improving Agricultural Water Sustainability: Strategies for Effective Farm Water Management and Encouraging the Uptake of Drip Irrigation. In D. Crowther, S. Seifi, \& A. Moyeen (Orgs.), The Goals of Sustainable Development (pp. 111-123). Singapore: Springer Singapore. https://doi.org/10.1007/978-981-10-5047-3_7

Herman, M. R., Nejadhashemi, A. P., Abouali, M., Hernandez-Suarez, J. S., Daneshvar, F., Zhang, Z., ... Sharifi, A. (2018). Evaluating the role of evapotranspiration remote sensing data in improving hydrological modeling predictability. Journal of Hydrology, 556, 39-49. https://doi.org/10.1016/j.jhydrol.2017.11.009 
Ma, Y., Liu, S., Song, L., Xu, Z., Liu, Y., Xu, T., \& Zhu, Z. (2018). Estimation of daily evapotranspiration and irrigation water efficiency at a Landsat-like scale for an arid irrigation area using multi-source remote sensing data. Remote Sensing of Environment, 216, 715-734. https://doi.org/10.1016/j.rse.2018.07.019

Moriasi, D. N., Arnold, J. G., Van Liew, M. W., Bingner, R. L., Harmel, R. D., \& Veith, T. L. (2007). Model evaluation guidelines for systematic quantification of accuracy in watershed simulations. Transactions of the ASABE, 50(3), 885-900. https://doi.org/10.13031/2013.23153

Nash, J. E., \& Sutcliffe, J. V. (1970). River flow forecasting through conceptual models part I-A discussion of principles. Journal of Hydrology, 10(3), 282-290. https://doi.org/10.1016/0022-1694(70)90255-6

Neville, A. M., \& Kennedy, J. B. (1964). Basic statistical methods for engineers and scientists. International Textbook.

Richter, K., Hank, T. B., Atzberger, C., \& Mauser, W. (2011). In C. M. U. Neale \& A. Maltese (Orgs.), Goodness-of-fit measures: What do they tell about vegetation variable retrieval performance from Earth observation data. https://doi.org/10.1117/12.897980

Robinson, N., Allred, B., Jones, M., Moreno, A., Kimball, J., Naugle, D., ... Richardson, A. (2017). A Dynamic Landsat Derived Normalized Difference Vegetation Index (NDVI) Product for the Conterminous United States. Remote Sensing, 9(8), 863. https://doi.org/10.3390/rs9080863

Rouse Jr, J., Haas, R., Schell, J., \& Deering, D. (1974). Monitoring vegetation systems in the Great Plains with ERTS.

Sales, D. L., Alves Júnior, J., Casaroli, D., Evangelista, A. W. P., \& Souza, J. M. F. (2018). Estimativa de evapotranspiração e coeficiente de cultura do tomateiro industrial utilizando o algoritmo SAFER. Irriga, 22(3), 629-640. https://doi.org/10.15809/irriga.2017v22n3p629-640

Silva, B. B. da, Braga, A. C., Braga, C. C., Oliveira, L. M. M. de, Montenegro, S. M. G. L., \& Barbosa Junior, B. (2016). Procedures for calculation of the albedo with OLI-Landsat 8 images: Application to the Brazilian semi-arid. Revista Brasileira de Engenharia Agrícola e Ambiental, 20(1), 3-8. https://doi.org/10.1590/ 1807-1929/agriambi.v20n1p3-8

Teixeira, A. de C., Hernandez, F. B. T., Lopes, H., Scherer-Warren, M., \& Bassoi, L. H. (2014). A comparative study of techniques for modeling the spatiotemporal distribution of heat and moisture fluxes at different agroecosystems in Brazil. Embrapa Semiárido-Capítulo em livro científico (ALICE).

Teixeira, A. H. de C. (2010). Determining regional actual evapotranspiration of irrigated crops and natural vegetation in the São Francisco River Basin (Brazil) using remote sensing and Penman-Monteith Equation. Remote Sensing, 2(5), 1287-1319. https://doi.org/10.3390/rs0251287

Toureiro, C., Serralheiro, R., Shahidian, S., \& Sousa, A. (2017). Irrigation management with remote sensing: Evaluating irrigation requirement for maize under Mediterranean climate condition. Agricultural Water Management, 184, 211-220. https://doi.org/10.1016/j.agwat.2016.02.010

Wahab, I., Hall, O., \& Jirström, M. (2018). Remote Sensing of Yields: Application of UAV Imagery-Derived NDVI for Estimating Maize Vigor and Yields in Complex Farming Systems in Sub-Saharan Africa. Drones, 2(3), 28. https://doi.org/10.3390/drones2030028

Willmott, C., \& Matsuura, K. (2005). Advantages of the mean absolute error (MAE) over the root mean square error (RMSE) in assessing average model performance. Climate Research, 30, 79-82. https://doi.org/ $10.3354 /$ cr030079

Zhang, H., Liu, P., He, L., Lian, Y., \& Cui, T. (2017). Effects of reflectance anisotropy on albedo retrieval from satellite observations (pp. 3144-3154). 2017 IEEE International Geoscience and Remote Sensing Symposium (IGARSS). https://doi.org/10.1109/IGARSS.2017.8127665

\section{Copyrights}

Copyright for this article is retained by the author(s), with first publication rights granted to the journal.

This is an open-access article distributed under the terms and conditions of the Creative Commons Attribution license (http://creativecommons.org/licenses/by/4.0/). 